\title{
Application of Decomposition Technique to Linear Wave Model Identification
}

Ching-Yaw Tzeng

Associate Professor, Institute of Maritime Technology, National Taiwan Ocean University, Keelung, Taiwan, R.O.C.

Follow this and additional works at: https://jmstt.ntou.edu.tw/journal

Part of the Engineering Commons

\section{Recommended Citation}

Tzeng, Ching-Yaw (1997) "Application of Decomposition Technique to Linear Wave Model Identification," Journal of Marine Science and Technology. Vol. 5: Iss. 1, Article 3.

DOI: 10.51400/2709-6998.2534

Available at: https://jmstt.ntou.edu.tw/journal/vol5/iss1/3

This Research Article is brought to you for free and open access by Journal of Marine Science and Technology. It has been accepted for inclusion in Journal of Marine Science and Technology by an authorized editor of Journal of Marine Science and Technology. 


\title{
APPLICATION OF DECOMPOSITION TECHNIQUE TO LINEAR WAVE MODEL IDENTIFICATION
}

\author{
Ching-Yaw Tzeng*
}

Keywords: Linear wave theory, Irregular wave, Wave identification, Decomposition technique.

\section{ABSTRACT}

A decomposition technique is employed in identifying the coefficients of a Fourier series-based linear wave model. Two decomposed subproblems are formulated, one in the frequency domain and one in the direction domain. Less computation time is required when solving the two subproblems sequentially, compare to solving the original problem directly. A stretched method that takes the instantaneous free surface as the reference position in computing the water particle velocities achieves better agreement with the experimental data than the standard linear approach where the reference position is taken at the mean water level.

\section{INTRODUCTION}

Linear wave theory is useful in many hydrodynamic applications and the formulation is of limited complexity [1]. However, the water particle velocities, being important to wave loading on offshore structures and marine vehicles, are not well described by the linear theory near the surface, especially under the crests. Stretched method has been introduced to cope with this problem $[2,3]$, which took the instantaneous free surface as the reference point in computing the water particle velocity rather than using the mean water level (MWL).

A decomposition technique developed by Miele et al. [4] was modified to identify the amplitudes of various wave components of specified frequency and direction. Both the wave elevation and the water particle velocity of the two-dimensional irregular

Paper Received November, 1996. Revised April, 1997. Accepted April, 1997. Author for Correspondence: Ching-Yaw Tzeng.

*Associate Professor, Institute of Maritime Technology, National Taiwan Ocean University, Keelung, Taiwan, R.O.C. waves were measured by Norwegian Hydrotechnical Laboratory (NHL). Only the elevation data were used in constructing the wave model. The measured velocity data were used exclusively in comparing with the computed velocity data. An effective wave absorber was built to eliminate the reflected waves [5], a onedirection wave model was considered adequate in analyzing the experimental wave data.

\section{EXPERIMENTAL ARRANGEMENTS}

The experiments were carried out at NHL wave tank. The tank was $33 \mathrm{~m}$ long, $1.02 \mathrm{~m}$ wide and $1.8 \mathrm{~m}$ deep (Fig. 1). The wave generator was located at one end of the tank and a wave absorber developed by the National Research Council of Canada was deployed at the other end of the tank. The reflection coefficient was about $5 \%$ over the frequency with most wave energy [5]. A plastic mat was used to reduce the high frequency reflections from the absorber and to reduce the cross waves. Seven wave gauges were placed along the tank to measure the wave elevations. Water particle velocity was measured at several different elevations by a laser Doppler velocimeter (LDV) [6], which was located at the same station as wave gauge \#1.

\section{EXPERIMENTAL DATA}

The wave data were sampled at a rate of $40 \mathrm{HZ}$ for a duration of $819.2 \mathrm{sec}$. Every 2 nd data point of the record was used in the FFT. Although the Nyquist frequency was $10 \mathrm{HZ}$, a cutoff frequency of $5 \mathrm{HZ}$ was

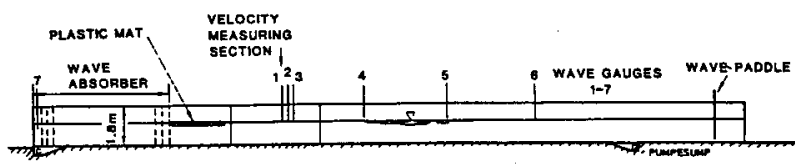

Fig. 1. Experimental Arrangements. 
used in the inverse FFT to eliminate possible induced high frequency waves. The analysis focused on the irregular waves with $1 / 1.65 \mathrm{HZ}$ peak frequency, 0.16 $\mathrm{m}$ significant wave height, and $1.3 \mathrm{~m}$ water depth. Specifically, three LDV locations were examined : MWL, $0.1 \mathrm{~m}$ below MWL and $0.5 \mathrm{~m}$ below MWL. The mean value of the measured elevation data was removed before being used to construct the wave model.

\section{METHEMATICAL FORMULATION}

\section{A. Original Problem : Problem P}

With the linear wave theory, the elevations of irregular waves can be written in the following Fourier series form [4]:

$$
\eta_{i}(t)=\sum_{m} \sum_{n} a_{m n} \cos \left(\psi_{m n i t}\right)+b_{m n} \sin \left(\psi_{m n i t}\right),
$$

where $\eta:=$ surface elevation,

$n:=$ number of wave direction, $\mathrm{n}=1 \sim \mathrm{N}$,

$m:=$ number of wave frequency, $m=1 \sim \mathrm{M}$,

$i:=$ number of wave gauges, $\mathrm{i}=1 \sim \mathrm{I}$,

$t:=$ time,

where

$$
\psi_{m n i t}=k_{m}\left(x_{i} \cos \theta_{n}+y_{i} \sin \theta_{n}\right)-\omega_{m} t,
$$

with linear dispersion relationship

$$
\omega_{m}^{2}=k_{m} \mathrm{~g}^{*} \tanh \left(k_{m} d\right)
$$

where $\omega_{m}:=m^{\text {th }}$ component frequency,

$k_{m}:=$ wave number corresponds to $\omega_{m}$,

$d:=$ water depth,

$g:=$ acceleration of gravity,

$q_{n}:=n^{\text {th }}$ wave direction,

$x_{i}, y_{i}:=\mathrm{x}, \mathrm{y}$ locations of gauge \# $\mathrm{i}$.

Now, define problem $P$ as follows:

given: $\tilde{\eta}_{i}(t)$ (measured elevation data)

find: $a_{m n}, b_{m n}$ that minimize

$I=\sum_{i} \int_{0}^{T}\left[\tilde{\eta}_{i}(t)-\eta_{i}(t)\right]^{2} d t$

This is a problem of size $2 \mathrm{MN}$, which could be expensive if $\mathbf{M}$ and $\mathrm{N}$ both are large.

\section{B. Decomposed Problem}

We can decompose problem $P$ by rewriting (1a) as follows:

$$
\begin{aligned}
\eta_{i}(t)= & \sum_{m} \sum_{n} a_{m n} \cos \left(k_{m} x_{i} \cos \theta_{n}+k_{m} y_{i} \sin \theta_{n}-\omega_{m} t\right) \\
& +b_{m n} \sin \left(k_{m} x_{i} \cos \theta_{n}+k_{m} y_{i} \sin \theta_{n}-\omega_{m} t\right) .
\end{aligned}
$$

Let $k_{m} x_{i} \cos \theta_{n}+k_{m} y_{i} \sin \theta_{n}=P_{m n i}$,

then (4) takes the following form:

$$
\begin{aligned}
\eta_{i}(t) & =\sum_{m} \sum_{n}\left[a_{m n} \cos \left(P_{m n i}-\omega_{m} t\right)+b_{m n} \sin \left(P_{m n i}-\omega_{m} t\right)\right] \\
& =\sum_{m} \sum_{n}\left\{a_{m n}\left[\cos P_{m n i} \cos \omega_{m} t+\sin P_{m n i} \sin \omega_{m} t\right]\right. \\
& \left.+b_{m n}\left[\sin P_{m n i} \cos \omega_{m} t-\cos P_{m n i} \sin \omega_{m} t\right]\right\} \\
& =\sum_{m} \sum_{n}\left\{\left(a_{m n} \cos P_{m n i}+b_{m n} \sin P_{m n i}\right) \cos \omega_{m} t\right. \\
& \left.+\left(a_{m n} \sin P_{m n i}-b_{m n} \cos P_{m n i}\right) \sin \omega_{m} t\right\} \\
& =\sum_{m}\left[A_{m i} \cos \omega_{m} t+B_{m i} \sin \omega_{m} t\right], \quad i=1 \ldots I
\end{aligned}
$$

and

$$
\begin{array}{cc}
A_{m i}=\sum_{n}\left(a_{m n} \cos P_{m n i}+b_{m n} \sin P_{m n i}\right), & \begin{array}{l}
m=1 \ldots M \\
i=1 \ldots I
\end{array} \\
B_{m i}=\sum_{n}\left(a_{m n} \sin P_{m n i}-b_{m n} \cos P_{m n i}\right), & \begin{array}{l}
m=1 \ldots M \\
i=1 \ldots I
\end{array}
\end{array}
$$

Now, two subproblems can be defined.

\section{Frequency Domain: Subproblem $\mathbf{Q}_{\mathbf{1}}$}

Given : $\tilde{\eta}_{i}(t)$ for each wave gauge $\mathrm{i}$

find : $A_{m i}, B_{m i}$ of all the frequencies that minimize

$J_{1}=\int_{0}^{T}\left\{\tilde{\eta}_{i}(t)-\sum_{m}\left[A_{m i} \cos \omega_{m} t+B_{m i} \sin \omega_{m} t\right]\right\}^{2} d t$.

We have I porblems here, each with size $2 \mathrm{M}$, where $M$ is the number of wave frequencies. The FFT is used in finding the unknowns, $A_{m i}, B_{m i}$. It is well known that with $A_{m i}, B_{m i}$ being the Fourier coefficients, the Fourier series expansions appear in Eq. (7) approximate the time function $\tilde{\eta}_{i}(t)$ in the mean square sense. Here $T$ corresponds to the time internal of the wave record and it is taken as the period in the Fourier series expansion.

\section{Direction Domain: Subproblem $\mathbf{Q}_{\mathbf{2}}$}

Given : $A_{m i}, B_{m i}$ for each frequency $\mathrm{m}$

find : $a_{m n}, b_{m n}$ of all the directions that minimize

$$
\begin{aligned}
J_{2} & =\sum_{i}\left[A_{m i}-\sum_{n}\left(a_{m n} \cos P_{m n i}+b_{m n} \sin P_{m n i}\right)\right]^{2} \\
& +\sum_{i}\left[B_{m i}-\sum_{n}\left(a_{m n} \sin P_{m n i}-b_{m n} \cos P_{m n i}\right)\right]^{2}
\end{aligned}
$$


We have $M$ problems here, each with size $2 \mathrm{~N}$, where $\mathrm{N}$ is the number of wave directions.

If $\mathrm{I}>\mathrm{N}$, then we have a least-square problem.

If $\mathrm{I}=\mathrm{N}$, then this reduced to solving a linear system of equations.

As a result, we have decomposed a problem $(P)$ of size $2 \mathrm{MN}$ into I frequency domain subproblems $\left(Q_{1}\right)$ of size $2 M$, and $M$ direction domain subproblems $\left(Q_{2}\right)$ of size $2 \mathrm{~N}$. It's clear that the CPU time is greatly reduced if $M$ and $N$ are large. Specifically, let's assume that the number of wave gauges $I=10$, the number of wave directions $\mathrm{N}=10$, and the number of wave frequencies $M=10$. Also note that in solving for a linear system of size $L$ by factorization method, the floating point operations are proportional to $\mathrm{L}^{3}$. Hence, the computation time required for the decomposed problem is approximately $1 / 50$ of the original problem The equivalence of problem $P$ to the decomposed subproblems $Q_{1}$ and $Q_{2}$ follows from the following arguments: "the summed error is minimized as long as each individual error terms is minimized". This is true as long as each individual error term is nonnegative. And it is indeed the case, since the individual error term is defined in a squared form. Moreover, the $A_{m i}, B_{m i}$ solved from subproblem $\mathrm{Q}_{1}$ being the Fourier coefficients. Hence, minimization of the performance index $J_{1}$ in the mean square sense is ensured.

\section{VELOCITY COMPUTATION METHODS}

\section{A. Standard Linear Approach}

From the linear wave theory, the horizontal and vertical water particle velocities are given by

$$
U_{i}(t)=\sum_{m} \sum_{n}\left[a_{m n} \cos \left(\psi_{m n i t}\right)+b_{m n} \sin \left(\psi_{m n i t}\right)\right] Q_{m n j},(9 \mathrm{a})
$$

and

$$
W_{i}(\mathrm{t})=\sum_{m} \sum_{n}\left[a_{m n} \sin \left(\psi_{m n i t}\right)-b_{m n} \cos \left(\psi_{m n i t}\right)\right] R_{m n j},(9 \mathrm{~b})
$$

where $j$ indicates vertical position dependency of the LDV, and the depth decay functions are given by

$$
Q_{m n j}=\omega_{m} \cos \theta_{n}\left\{\frac{\cosh \left(k_{m} Z_{j}+k_{m} d\right)}{\sinh \left(k_{m} d\right)}\right\},
$$

and

$$
R_{m n j}=\omega_{m}\left\{\frac{\sinh \left(k_{m} Z_{j}+k_{m} d\right)}{\sinh \left(k_{m} d\right)}\right\},
$$

where $Z_{j}$ is the vertcal position of the LDV (measured from MWL).

For the case here, LDV is located at $\mathrm{x}=0, \mathrm{y}=0 ;$ \& $\theta_{1}=0^{\circ}$ (incident wave), $\theta_{2}=180^{\circ}$ (reflected wave). Hence, Eqs. (9) are reduced to a simpler form:

$$
\begin{aligned}
U(Z, t) & =\sum_{m}\left[a_{m 1} \sin \left(\omega_{m} t\right)-b_{m 1} \cos \left(\omega_{m} t\right)\right] \omega_{m} \\
& \frac{\cosh \left(k_{m}(Z+d)\right)}{\sinh \left(k_{m} d\right)}-\sum_{m}\left[a_{m 2} \cos \left(\omega_{m} t\right)\right. \\
& \left.-b_{m 2} \sin \left(\omega_{m} t\right)\right] \omega_{m} \frac{\cosh \left(k_{m}(Z+d)\right)}{\sinh \left(k_{m} d\right)},
\end{aligned}
$$

and

$$
\begin{aligned}
W(Z, t) & =\sum_{m}\left[-a_{m 1} \sin \left(\omega_{m} t\right)-b_{m 1} \cos \left(\omega_{m} t\right)\right] \omega_{m} \\
& \frac{\sinh \left(k_{m}(Z+d)\right)}{\sinh \left(k_{m} d\right)}-\sum_{m}\left[-a_{m 2} \cos \left(\omega_{m} t\right)\right. \\
& \left.-b_{m 2} \sin \left(\omega_{m} t\right)\right] \omega_{m} \frac{\sinh \left(k_{m}(Z+d)\right)}{\sinh \left(k_{m} d\right)},(1
\end{aligned}
$$

where $\mathrm{U}(\mathrm{Z}, \mathrm{t})$ is the horizontal water particle velocity and $W(Z, t)$ is the vertical water particle velocity at elevation $Z$ at time $t$.

\section{B. Stretched Approach}

With the nonlinearly stretched linear approach, we computed velocity components $\mathrm{U}, \mathrm{W}$ with Eqs (11), except that in the depth decay functions $Q$ and $R$ (Eqs. (10)), replace $Z$ with $Z^{\prime}$, where $Z^{\prime}$ is obtained from the following equation:

$$
Z=Z^{\prime}+\eta\left\{\frac{\sinh \left(k_{p}\left(Z^{\prime}+d\right)\right)}{\sinh \left(k_{p} d\right)}\right\}
$$

where $\eta$ is the elevation computed form Eq. (4), $d$ is the water depth and $k_{p}$ is the wave number corresponding to $\omega_{p}$, the spectral peak frequency.

\section{NUMERICAL RESULTS}

As the experimental data indicated small reflection coefficient (about 5\%) over the frequency range with significant energy, it was justified to analyze the laboratory wave data with a one-direction wave model. Numerical results presented here were made for three LDV locations: one at MWL $(\mathrm{z}=0.00$ $\mathrm{m})$, one at $0.1 \mathrm{~m}$ below the MWL $(\mathrm{z}=-0.10 \mathrm{~m})$ and one at $0.5 \mathrm{~m}$ below MWL $(\mathrm{z}=-0.50 \mathrm{~m})$.

\section{A. Employment of Wave Gauge \#1}

A segment of $6 \mathrm{sec}$. in the record (48-54 sec.) was examined. With one-direction/ one-gauge model, the direction domain least-square problem reduced to a linear system of equations, which could be solved 
exactly. Hence, a perfect match in surface elevation would be obtained if the inverse FFT included all frequencies up to the Nyquist frequency $(10 \mathrm{HZ})$. As a pre-selected $5 \mathrm{HZ}$ cutoff frequency was used, a very small difference between the measured and computed surface elevations could be observed (Fig. 2A). The spectra of the computed elevation were given in Fig. 2B. As could be seen, the peak frequency was about $1 / 1.65 \mathrm{HZ}$, which was the value used in generating the irregular waves.

Under the crests, the instability of the standard linear theory was especially noticeable when the LDV was located at the MWL (Figs. 3A , 3B). Stretching improved the quality of prediction for both the horizontal velocity $U$ and the vertical velocity $W$ (Figs. 3C, 3D). The superiority of stretching under the crests still existed when the LDV was located below the MWL(at $\mathrm{z}=-0.10 \mathrm{~m}$ ). Specifically, the standard linear theory overpredicted U (Fig. 4A), and the stretching predicted quite well (Fig. 4C). The quality of prediction for $\mathrm{W}$ was basically the same (Figs. 4B, 4D).

As the LDV was located further below the MWL (at $\mathrm{z}=-0.5 \mathrm{~m}$ ), the difference between the

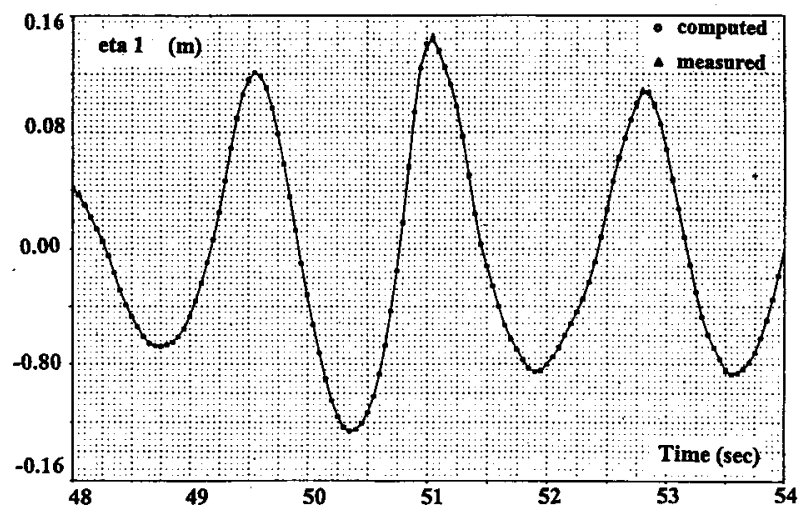

Fig. 2A. Elevation at Gauge \#1.

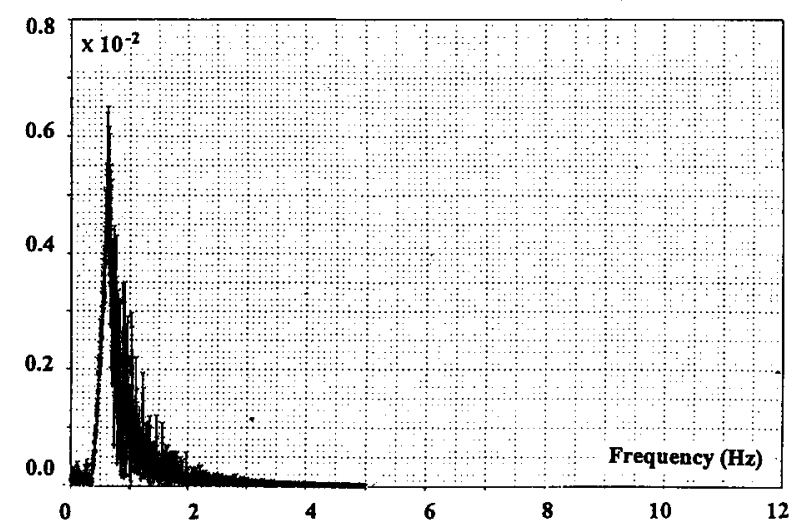

Fig. 2B. Incident Wave Spectra.
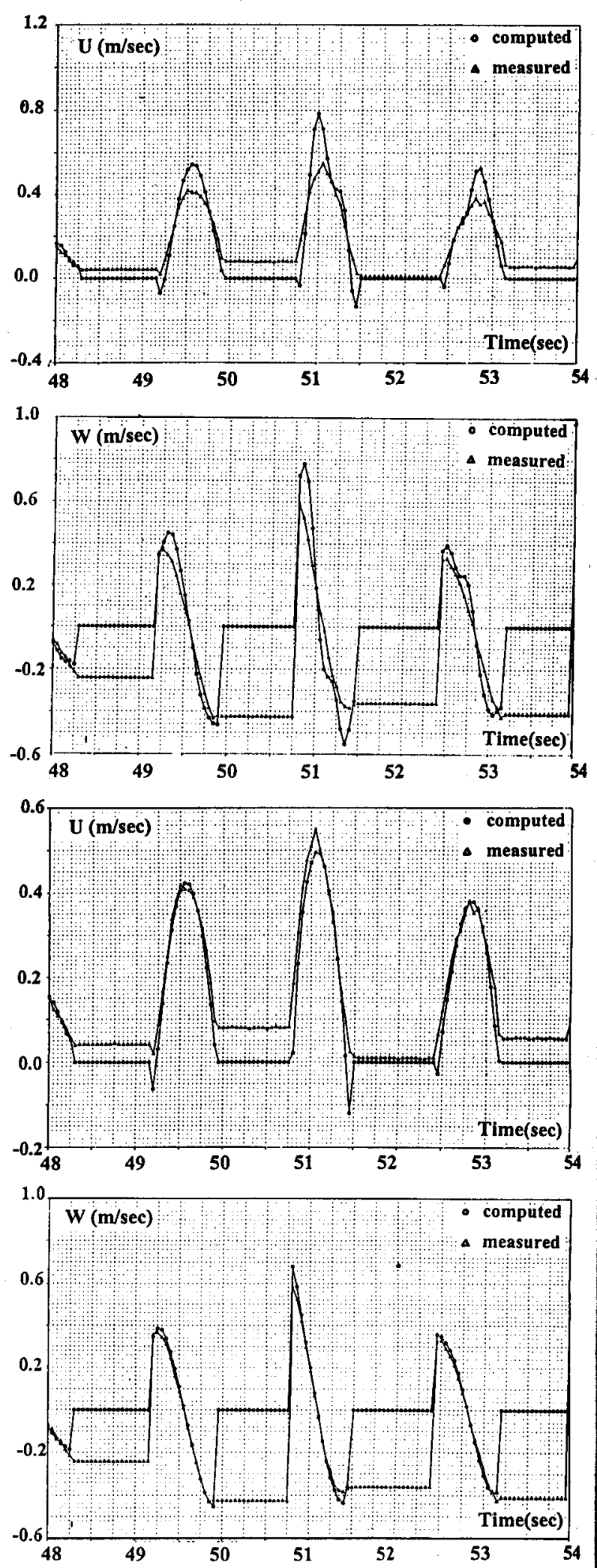

Fig. 3A. Horizontal Vel. (Linear); LDV@z=0.0 m.

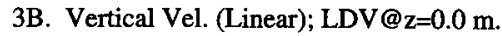

3C. Horizontal Vel. (Stretched); LDV@ $\mathrm{z}=0.0 \mathrm{~m}$

3D. Vertical Vel. (Stretched); LDV @ $\mathrm{z}=0.0 \mathrm{~m}$ 

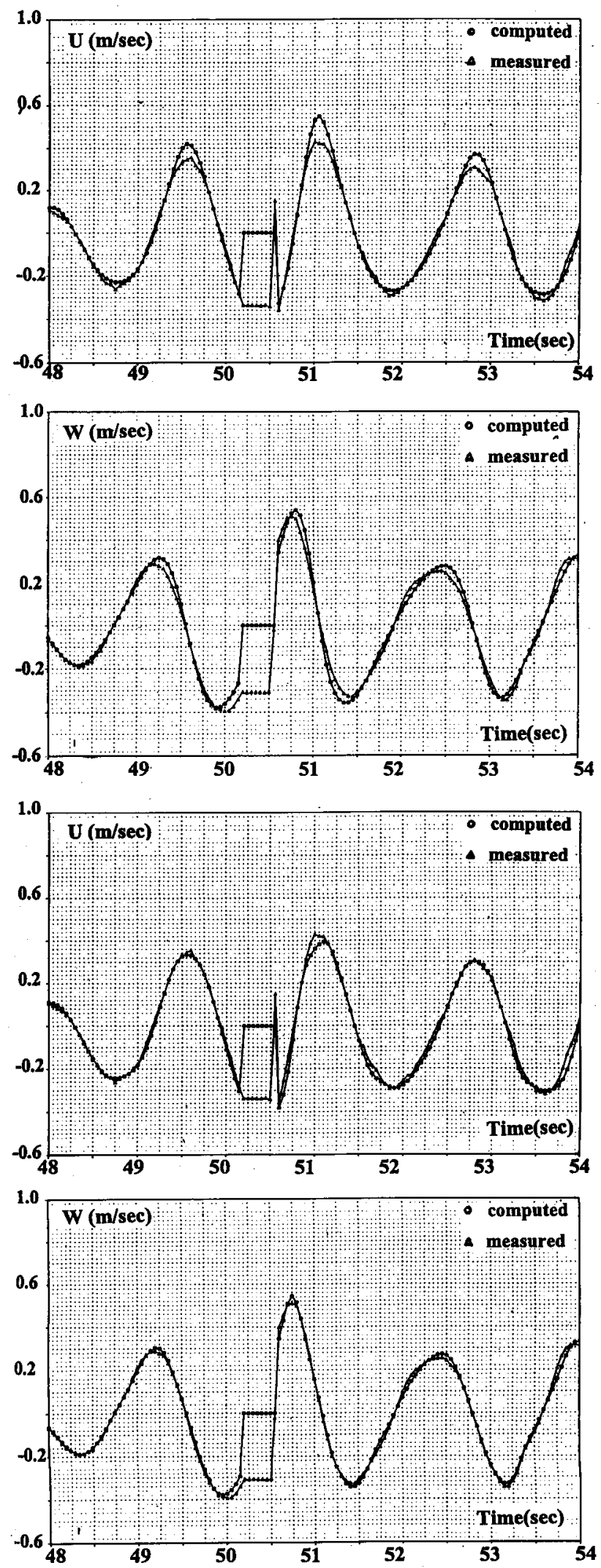

Fig. 4A. Horizontal Vel. (Linear); LDV@z=-0.1 m.

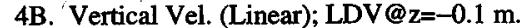

4C. Horizontal Vel. (Stretched); LDV@z=-0.1 m.

4D. Vertical Vel. (Stretched); LDV@ $\mathrm{z}=-0.1 \mathrm{~m}$
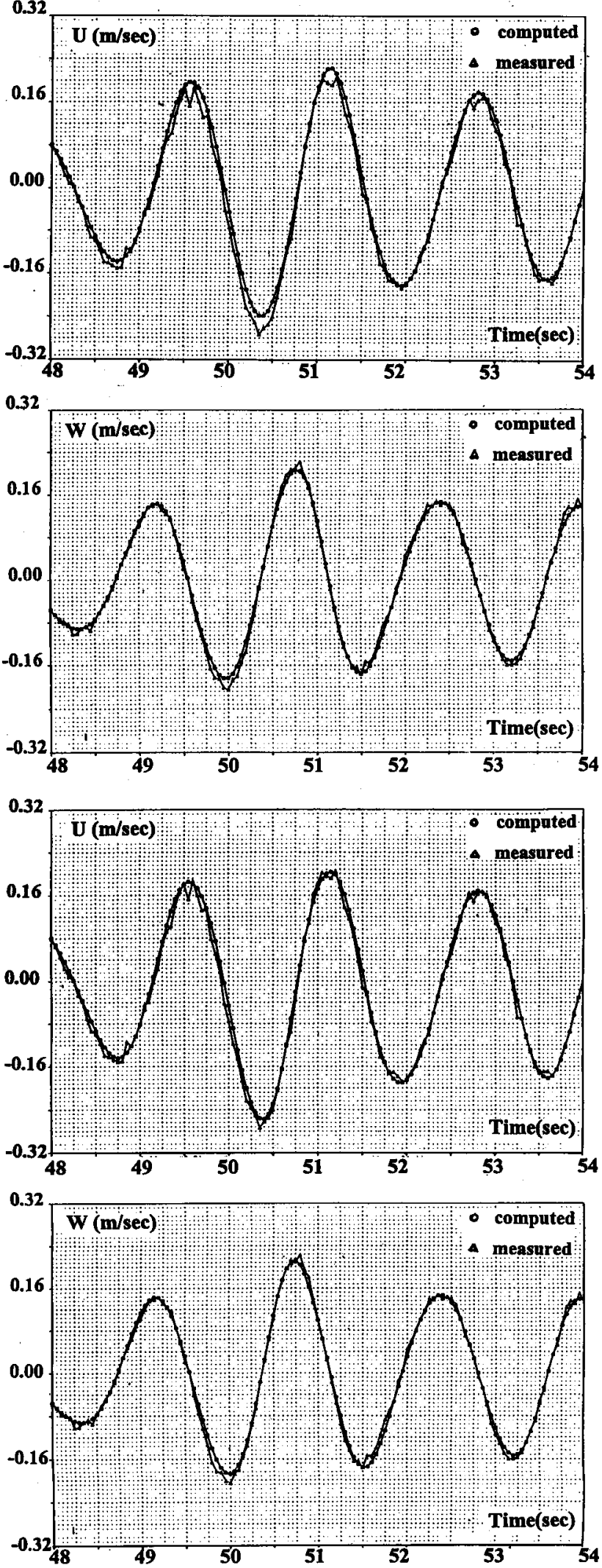

Fig. 5A. Horizontal Vel. (Linear); LDV@z=-0.5 m.

5B. Vertical Vel. (Linear); LDV@z $=-0.5 \mathrm{~m}$.

5C. Horizontal Vel. (Stretched); LDV@z=-0.5 m.

5D. Vertical Vel. (Stretched); LDV@ $\mathrm{z}=-0.5 \mathrm{~m}$ 
two approaches disappears and the quality of prediction for horizontal velocity $U$ (Figs. 5A, 5C) and vertical velocity $\mathrm{W}$ (Figs. 5B, 5D) were basically the same.

\section{B. Employment of Other Wave Gauge}

Since the LDV was located at the same station as wave gauge \#1, a perfect match in surface elevation at \#1 gauge was very likely to produce a good water particle velocity prediction, and it was indeed the case as previously discussed. However, a good velocity prediction at \#1 gauge did not guarantee good quality of velocity at other locations, since the linear dispersion relationship might not propogate the higher-order random waves properly.

With the wave gauge \#1 replaced by wave gauge \#3, a perfect surface elevation match at gauge \#3 is still obtained (Fig. 6A); however, the elevation prediction is poor at gauge \#1 where the LDV is located (Fig. 6B).

For LDV location at $\mathrm{z}=-0.1 \mathrm{~m}$, the predic-

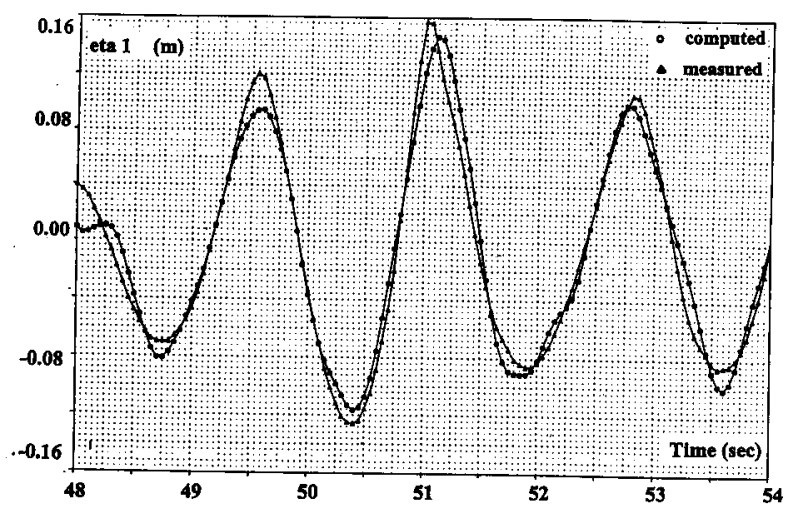

Fig. 6A. Elevation at Gauge \#1.

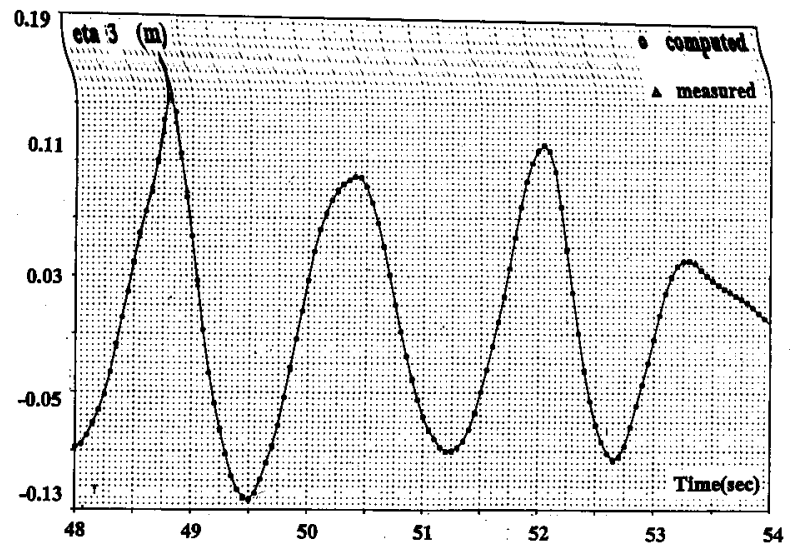

Fig. 6B. Elevation at Gauge \#3.
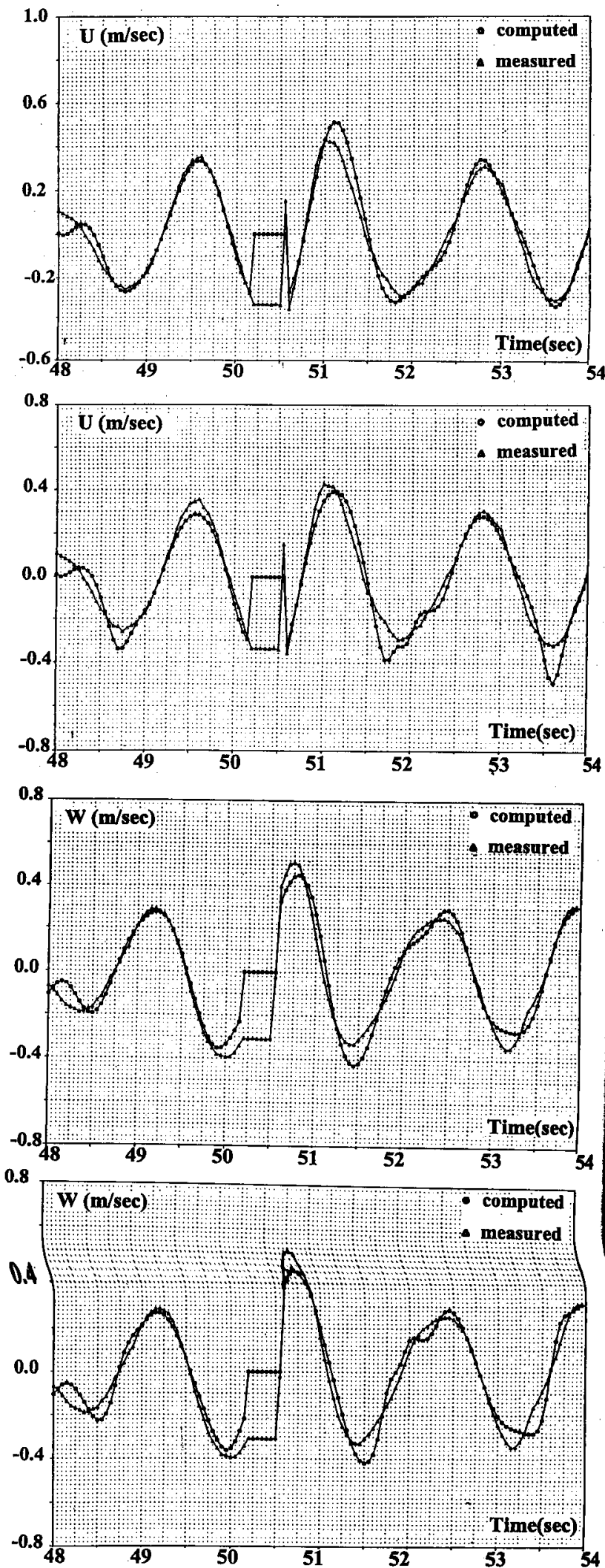

Fig. 7A. Horizontal Vel. (Linear); LDV@z=-0.1 m.

7B. Vertical Vel. (Linear); LDV@z=-0.1 m.

7C. Horizontal Vel. (Stretched); LDV@ $\mathrm{z}=-0.1 \mathrm{~m}$.

7D. Vertical Vel. (Stretched); LDV@ $\mathrm{z}=-0.1 \mathrm{~m}$ 
tion quality of water particle velocities was degraded for both the linear approach (Figs 7A, 7B) and the stretched approach (Figs. 7C, 7D), as compared with the previous case where gauge \#1 was used (Figs. 4A4D).

\section{CONCLUSIONS}

A linear wave model is identified via a decomposition technique, which transforms the original least-square problem into two subproblems. Numerical results indicate that the one-direction (incident) wave model conditioned with a single wave gauge (directly above the LDV) provides good velocity prediction. Stretched approach is better than standard linear approach in predicting irregular wave particle velocity near the free surface especially under the crests. At locations further below the MWL, the difference in the quality of velocity prediction with these two approaches disappears. With the proposed decomposition technique, computation time is less demanding for the wave model identification problem.

\section{REFERENCES}

1. Newman, J.N. " Marine Hydrodynamics," The MIT Press, Cambridge, Massachusetts (1977).

2. Chakrabarti, S.K., "Disscussion on Dynamics of Single Point Mooring in Deep Water," J. Waterways, Harbour and Coastal Eng. Div. ASCE, Vol. 97, pp. 588-590 (1971).

3. Wheeler, J.D., "Method for Calculating Forces Produced by Irregular Waves," J. Petroleum Tech., March, pp. 119-137 (1970).

4. Miele, A., Wang, T., Zhao, X.G. and Heideman, J.C., "Decomposition Techniques for the Ocean Wave Identification Problem," J. Optimization Theory and Appl., Vol. 51, No.1, pp. 1-39 (1986).

5. Jamieson, W.W. and Mansard, E.P.D., "An Efficient Upright Wave Absorber," ASCE Speciality Conferences on Coastal Hydrodynamics. University of Delaware, June (1987).

6. Skjelbreia, J., "Observations of Breaking Waves on Sloping Bottom by Use of Laser Doppler Velocimetry," Ph.D. Thesis, California Institute of Technology, Pasadena, California, (1987).

\section{分解法在線性波模式篮定之應用}

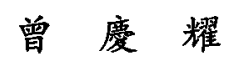

海洋大掌航運技衔研究所

摘 要

本文針對一以富利菜級數来描述之線性波模 式進行鑑定工作。原命題可分解為一在 “頻域”及 一在 “方向域” 雨個子問題, 處理子問題所需之計 算時間較原問題為少。水分子運動速度則分別以“ 線性法”及“伸張法”來計算。就估測水分子運動 速度之精確性而言, 伸張法較線性法為佳, 其原因 在於後者以瞬間水面位置作為計算基準點而前者則 以平均水面位置為計算基準點。 